\title{
Risk Assessment in the Maritime Industry
}

\author{
Majid Mousavi \\ Department of Disaster Management \\ Shakhes Pajouh Research Institute \\ Isfahan, Iran \\ majidmousavi73@gmail.com
}

\author{
Iran Ghazi \\ Department of Disaster Management \\ Shakhes Pajouh Research Institute \\ Isfahan, Iran \\ iranghazi20@gmail.com
}

\author{
Behrooz Omaraee \\ Islamic Azad University \\ Kharg Branch \\ Kharg Island, Iran \\ b.omaraee@gmail.com
}

\begin{abstract}
Risk assessment is a well-developed field which many operators are currently applying to improve their operations and reduce their risk exposure. This paper is intended to provide an overview of the risk assessment for mariners in the Maritime transportation. The risks addressed are primarily those affecting the safety of a vessel, facility or operation. The concept of risk is defined, and the methods available to assess the risks associated with an operation are described. Regulatory requirements that have prompted the development of modern risk assessment practices are described, and future regulatory trends are discussed. There are many different analysis techniques and models that have been developed to aid in conducting risk assessments. A key to any successful risk analysis is choosing the right method (or combination of methods) for the situation at hand. This is achieved through critical analysis of the available data concerning marine crises. This paper provides a brief introduction to some of the analysis methods available and suggests risk analysis approaches to support different types of decision making within the maritime transportation to cope with crises. Finally, as awareness of risk assessment increases, the benefits which can be realized through its application will continue to increase. Organizations in both the public and the private sector are becoming more and more familiar with the benefits associated with risk-based approaches to managing safety and consequently reducing crisis in maritime transportation.
\end{abstract}

\section{Keywords-Risk assessment; Maritime; Crisis; Vessel}

\section{INTRODUCTION}

Risk assessment is typically applied as an aid to the decision-making process. As options are evaluated, it is critical to analyze the level of risk introduced with each option. The analysis can address financial risks, health risks, safety risks, environmental risks and other types of business risks. An appropriate analysis of these risks will provide information which is critical to good decision making, and will often clarify the decision to be made. The information generated through risk assessment can often be communicated to the organization to help impacted parties understand the factors which influenced the decision. Risk assessment is the process of gathering data and synthesizing information to develop an understanding of the risk of a particular enterprise. A detailed step by step guide to risk assessment follows in the next section. The guide is written in a follow-though fashion to provide a clear guidance path.

\section{STEPS OF RISK ASSESSMENT}

The first obvious step would be to identify the risks involved (step 1). The risks should be grouped under appropriate risk headings. One should consider the effect on people (staff, students and other people), information, physical assets and finances, reputation. The next step is to determine the consequences and likelihood of each risk using a predetermined scale (e.g. Table I) (step 2). One should also consider the consequences to evaluate the risk level (Table II) (step 3). Next, further risk treatments and opportunities for improvement should be considered (step 4). In this step, one should consider the actions needed to bring risks to an acceptable level and whether these actions are incorporated into other planning processes and include responsibilities, resources and timelines. The improvement opportunities should be considered. Communication, consulting, monitoring and reviewing should be incorporated throughout the process. The assessment should be reviewed on a regular basis. The final step (step 5) is filing the documentation.

Risk assessment approaches are increasingly commonly used for the assessment of major hazards and the demonstration that risks have been controlled to an as low as reasonably practicable (ALARP) standard. Attitudes have changed in the oil industry from an initial position of skepticism to good support for the simpler approaches, and for the clarity of focus this brings to controlling hazards, but with still some question as to the effectiveness of quantitative risk assessment Health \& Safety at Work etc Act 1974 (QRA). For example, the regulations applying to offshore operations in the UK, including Health \& Safety at Work etc Act 1974(HSWA), MHSWR and Offshore Installations Safety Case Regulations 1992(SCR), require operators to undertake risk assessment in order to identify appropriate measures to protect people against crises, so far as is reasonably practicable. SCR includes specific requirement for QRA, but this does not apply to marine hazards, i.e. hazards connected with the interface between the installation and the marine environment. Perhaps as a consequence, the risk assessments of marine hazards in the safety cases submitted to date have been less thorough than the treatment of hazards from fire and explosions [1]. The safety of offshore installations against marine hazards has traditionally relied on IMO legislation and classification society rules. These rules have been developed by expert judgment, responding to previous crisis experience, and in general prescribe specific 
design solutions. They are only rarely based on risk assessment, and do not by themselves satisfy the requirement to perform a risk assessment. Modern risk management approaches make clear that risk assessment has an important role to play in many risk-related decisions, particularly for decisions involving uncertainty, deviation from standard practice and risk trade-offs, for which marine regulations are less appropriate. The United Kingdom Offshore Operators Association (UKOOA) decision support framework provides a suitable basis for such decision-making. The HSE tolerability of risk framework shows how risk assessment can contribute to such decisions [1].

TABLE I. CONSEQUENCES AND LIKELIHOOD OF EACH RISK

\begin{tabular}{|c|c|c|c|}
\hline \multicolumn{2}{|c|}{ Consequences } & \multicolumn{2}{c|}{ Likelihood } \\
\hline Level & Descriptor & Level & Descriptor \\
\hline $\mathbf{1}$ & Insignificant & A & Almost certain \\
\hline $\mathbf{2}$ & Minor & B & Likely \\
\hline $\mathbf{3}$ & Moderate & C & Possible \\
\hline $\mathbf{4}$ & Major & D & Unlikely \\
\hline $\mathbf{5}$ & Catastrophic & E & Rare \\
\hline
\end{tabular}

TABLE II. IDENTIFYING THE RISK LEVEL

\begin{tabular}{|l|l|l|l|l|l|}
\hline \multirow{2}{*}{ Likelihood } & \multicolumn{5}{|c|}{ Consequences } \\
\cline { 2 - 6 } & $\begin{array}{c}\text { Insignificant } \\
1\end{array}$ & $\begin{array}{c}\text { Minor } \\
2\end{array}$ & $\begin{array}{c}\text { Moderate } \\
3\end{array}$ & $\begin{array}{c}\text { Major } \\
4\end{array}$ & $\begin{array}{c}\text { Catastrophic } \\
5\end{array}$ \\
\hline $\begin{array}{l}\text { A-almost } \\
\text { certain }\end{array}$ & High & High & Extreme & Extreme & Extreme \\
\hline B-likely & Moderate & High & High & Extreme & Extreme \\
\hline C-possible & Low & Moderate & High & Extreme & Extreme \\
\hline $\begin{array}{l}\text { D- } \\
\text { unlikely }\end{array}$ & Low & Low & Moderate & High & Extreme \\
\hline E-rare & Low & Low & Moderate & High & High \\
\hline
\end{tabular}

III. HAZARD IDENTIFICATION (HAZID) TECHNIQUE

HAZID is a general term used to describe an exercise whose goal is to identify hazards and associated events that have the potential to result in a significant consequence. For example, a HAZID of an offshore petroleum facility may be conducted to identify potential hazards which could result in consequences to personnel (e.g., injuries and fatalities), environmental (oil spills and pollution), and financial assets (e.g., production loss/delay). The HAZID technique can be applied to all or part of facility or vessel or it can be applied to analyze operational procedures. Depending upon the system being evaluated and the resources available, the process used to conduct a HAZID can vary. Typically, the system being evaluated is divided into manageable parts, and a team is led through a brainstorming session (often with the use of checklists) to identify potential hazards associated with each part of the system. This process is usually performed with a team experienced in the design and operation of the facility, and the hazards that are considered significant are prioritized for further evaluation [3].

\section{CHECK LIST ANALYSIS}

Checklist analysis is a systematic evaluation against preestablished criteria in the form of one or more checklists. It is applicable for high-level or detailed-level analysis and is used primarily to provide structure for interviews, documentation reviews and field inspections of the system being analyzed. The technique generates qualitative lists of conformance and nonconformance determinations with recommendations for correcting non-conformances. Checklist analysis is frequently used as a supplement to or integral part of another method (especially what-if analysis) to address specific requirements [3].

\section{HAZARD AND OPERABILITY (HAZOP) ANALYSIS}

The HAZOP analysis technique uses special guidewords to prompt an experienced group of individuals to identify potential hazards or operability concerns relating to pieces of equipment or systems. Guidewords describing potential deviations from design intent are created by applying a predefined set of adjectives (i.e. high, low, no, etc.) to a predefined set of process parameters (flow, pressure, composition, etc.). The group then brainstorms potential consequences of these deviations and if a legitimate concern is identified, they ensure that appropriate safeguards are in place to help prevent the deviation from occurring. This type of analysis is generally used on a system level and generates primarily qualitative results, although some simple quantification is possible. The primary use of the HAZOP methodology is identification of safety hazards and operability problems of continuous process systems (especially fluid and thermal systems [3].

\section{CONTRIBUTION OF “HUMAN FACTORS” ISSUES}

In any effort to identify hazards and assess their associated risks, there must be full consideration of the interface between the human operators and the systems they operate. Human Factors Engineering (HFE) issues can be integrated into the methods used to identify hazards, assess risks, and determine the reliability of safety measures. For instance, hazard identification guidewords have been developed to prompt a review team to consider human factor design issues like access, control interfaces, etc [2]. An understanding of human psychology is essential in estimating the effectiveness of procedural controls and emergency response systems. Persons performing risk assessments need to be aware of the human factors impact, and training for such persons can improve their ability to spot the potential for human contributions to risk. Risk analysts can easily learn to spot the potential for human error any time human interaction is an explicit mode of risk control. However, it is equally important to recognize human contributions to risk when the human activity is implicit in the risk control measure. For example, a risk assessment of a boiler would soon identify "overpressure" as a hazard that can lead to risk of rupture and explosion. A checklist of common errors or an audit of the management system for operator training are examples of methods used to address the human error potential and ensure that it also is controlled [4]. The purpose of any tool would be to identify the potential for error and identify how the error is prevented.

- Does the operator know what the alarm means?

- Does he know how to shut down the boiler? 
- What if the overpressure event is one of a series of events (e.g. what if the operator has five alarms sounding simultaneously)?

- Did the engineer properly size and specify the relief valve?

- Was it installed correctly?

- Has it been tested or maintained to ensure its function?

A corollary to each of the above questions is required in the analysis: "How do you know?" The answer to that last question is most often found in the management system, thus "Human Factors" is the glue that ties risk assessment from a technology standpoint to risk assessment from an overall quality management standpoint [3].

\section{HAZARD IDENTIFICATION DURING PROJECT DEVELOPMENT}

Hazard identification is most effectively applied early in a project's life-cycle. If hazards can be identified early, they can often be "designed out" or eliminated completely during the early design phases of a project. If the hazards are not recognized until the design is complete or the system is operational, they will be more costly to address, and the only feasible way to address the hazards may be to provide measures to mitigate the hazardous events they may cause [2]. It is best to integrate hazard identification activities into the project development process to assure these activities are conducted at optimal times. For instance, high level Preliminary Hazards Analysis should be conducted as early as possible in the project life-cycle, while multiple project options are under consideration. This will enable risk assessment of the various options and help identify the major hazards which will need to be dealt with as the project goes forward. As the development process progresses, more and more detailed hazard analyses can be conducted. In the offshore oil and gas industry, hazard identification is typically performed on process systems during conceptual design(when process flow diagrams and layouts are available) and again at the detailed design phase (when P \& ID's and equipment specifications are available) [3].

\section{EVALUATION OF SAFEGUARDS}

Since the hazards relating to oil and gas production facilities are generally well understood, safeguards and preventive measures have become fairly standard across the industry. However, each project has its own unique requirements as a result of the types and amounts of fluids handled, the location, existing infrastructure, manning philosophy and other parameters. Safeguards must be customized for each project to adequately protect the facility. In order to evaluate safeguards, specialized safety studies are often applied. Companies designing major new offshore facilities typically conduct a suite of these studies, including [2]:

- Fire and Explosion Risk Analysis.

- Equipment Layout Review and Optimization.
- Evacuation, Escape and Rescue Analysis.

- Emergency Systems Survivability Analysis.

\section{MANAGEMENT OF CHANGE}

After a system is in operation, hazard identification is sometimes required by regulatory authorities as a design and operational check or to assure that changes made subsequent to the initial design have not introduced new hazards [2].

\section{RoOT CAUSE ANALYSIS}

Despite efforts to safeguard against all hazards during the design and specification of a facility, systematic analyses and strong management systems cannot completely eliminate the possibility of reliability-related problems. When failures occur, root cause analysis can be used to identify the underlying reasons (hazards and pre-conditions) that problems occur and to correct the root causes so that the same problem or related problems with shared root causes do not occur in the future. The root causes of an event are the most basic causes of an event that (1) can be reasonably identified and (2) management has the control/influence to fix. Typically, root causes are the absence, neglect, or deficiencies of management systems that control human actions and equipment performance [4].

\section{EVAlUATING NEW OPERATING MODES}

Over the years, standard approaches have been developed for operating oil and gas related equipment. Many of these have been documented as industry standards and/or codified into regulation. For example, regulatory bodies such as the U.S.'s OSHA and Coast Guard require adherence to basic standards in the areas of Hearing Conservation, Lock-out/Tagout, Fall Protection, Electrical Safety, Fire Protection, Emergency Response, etc. In addition, most operators have developed internal requirements to address recognized operational hazards [4]. In efforts to continually improve business performance, successful operators continue to challenge the established ways of conducting their operations. Opportunities for improved business performance are continually identified, and must be assessed for risk impact in addition to financial impact and feasibility. Risk studies can be conducted to assess the relative risks associated with various modes of operation, including [4] :

- Simultaneous Operations (Concurrent Production and/or Drilling and/or Construction Operations)

- Construction Activities: (Hazard analysis of construction activities, Risk impact of major marine activities at producing locations, etc.) .

- Automation of Drilling Activities.

- Production and Maintenance Activities (Manned vs. unmanned platforms, Platform-based maintenance crews vs. roving maintenance teams, etc.) [3]. 


\section{ESTIMATING OVERALL FACILITY RISKS}

In the North Sea, it has become an industry norm to use Quantified Risk Assessment (QRA) methods to estimate the Individual Risk Rate (annual potential of loss of life for an individual working on the facility) for Safety Case submittals to demonstrate that the risk associated with a particular platform is ALARP. Due to the potential for data and modeling uncertainties, and the assumptions made, the accuracy of such explicit risk rate calculations is not considered to be very good, and may be off by over $100 \%$. Unless specifically required by regulation (North Sea Safety Cases), the calculation of individual risk rates does not typically prove to be a useful way to devote risk assessment resources. Many operators prefer instead to conduct focused relative risk studies of a smaller scope to aid in making decisions between two or more viable options. When comparing the relative risks of two or more options, the same methodology and assumptions can be used to evaluate each option, and the uncertainties associated with the absolute risk numbers calculated does not significantly impact the decision. Often, high-level estimates of overall facility risks and the major risk contributors are made early in the project life to aid in selecting between various development options. This is a valuable exercise, because it is at this point that a project team has the most impact on the overall risks associated with the project. Conducting hazard and risk assessments early in the project life also allows time for the development of mitigation solutions to address major risk contributors [3].

\section{ACCIDENT COSTS}

\section{A. 1Accident cost models}

Accident cost information is important for estimating the benefits of risk control measures that reduce crisis probability, as required for the cost-benefit step of the Formal Safety Assessment procedure [4]. A basic loss matrix for ship accidents, considering the crisis categories collision, contact and grounding, consequences can result in impacts on humans (crew, passengers, and third parties), ships, the environment, industry, and the waterways and their future use, Ship owners, government services such as search and rescue providers, spill response agencies, fairway maintenance, and crisis investigation services may all incur direct costs as a result of crises (Figure 1). If environmental damage occurs, there will be many indirect costs to other users of the resource, including tourism and recreational users [5-8].

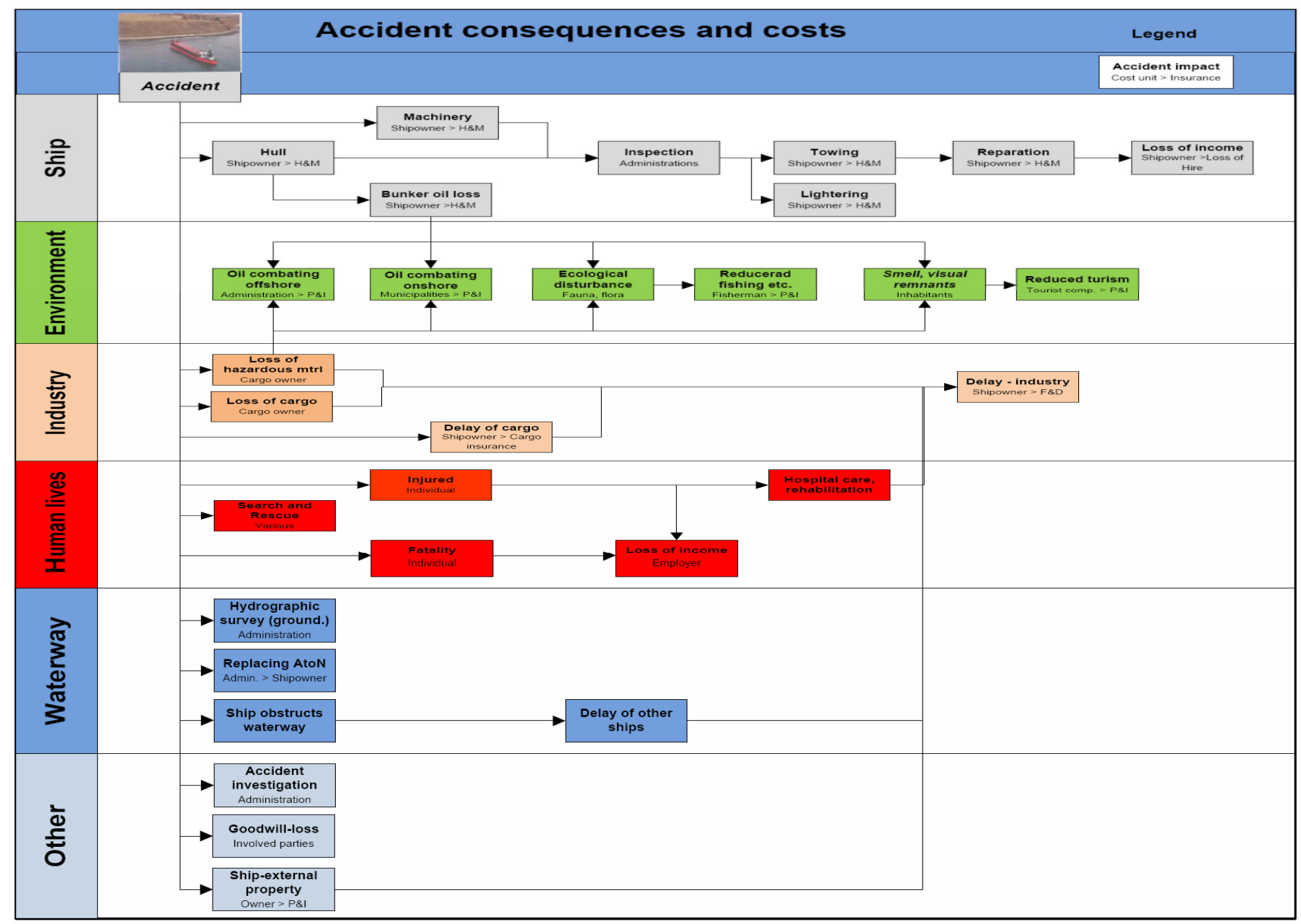

Fig. 1. Simplified model of accident consequences origon by collision, contact, and grounding crises. 


\section{CONCLUSION}

The primary goal of many risk assessments is to identify the hazards that are involved in a particular process or system and to develop adequate safeguards to prevent or reduce negative consequences from the related hazardous events. As previously discussed, the first step in performing a risk assessment is hazard identification. Whether done in an explicit or implicit form, this step provides an understanding of the basic hazards. The hazard identification step is a key factor in developing an understanding of the contributors to the risk of operating a particular system or process. Once these hazards are identified and the potential undesirable events involving these hazards are described, risk assessment techniques can allow personnel to identify the safeguards, or risk-reducing measures, that are currently in place and to make recommendations for additional safeguards that would further reduce the risk. These safeguards can either prevent an event from occurring, or reduce (mitigate) the consequences if an event does occur. Risk assessment is a well-developed field which many operators are currently applying to improve their operations and reduce their risk exposure. In many areas of the offshore and marine industries there is a dichotomy: operators must still comply with prescriptive "old-style" regulations while being encouraged on other fronts to develop a risk-based approach to safety. Risk assessment should be at the core of any safety-related rule-making or regulatory development process. Since the underlying goal of these rules and regulations is to reduce the risk of losses resulting from hazards, risk assessment seems an imperative part of any rule-making process. As awareness of risk assessment increases, the benefits which can be realized through its application will continue to increase.

\section{REFERENCES}

[1] Det Norske Veritas, Marine risk assessment, Offshore technology report 2001/063, Crown, 2002

[2] H. A. Oltedal, Safety culture and safety management within the Norwegian-controlled shipping industry, PhD Thesis, Faculty of Social Sciences, University of Stavanger, 2011

[3] ABS, ABS Guidance notes on risk assessment, 2000

[4] M. Lundkvist, Risk värdering avsjötrafik information, Draft Report, Swedish Maritime Administration,Vol. 1, No. 1, pp. 12-23, 2010

[5] R. F. Oy, P. Iikkanen, M. Mukula, "FMA, Alusliikenteen onnettomuuksien kustannukset" Merenkulkulaitoksen Julkaisuja, Helsinki, Finland, 2008 [in Finnish]

[6] J. Ylitalo, Modelling marine accident frequency, Msc Thesis, Aalto University, 2010.

[7] F. Goerlandt, J. Montewka, "Maritime transportation risk analysis: review and analysis in light of some foundational issues", Reliability Engineering \& System Safety, Vol. 138, No. 1, pp. 115-134, 2015

[8] A. Lehikoinen, M. Hänninen, J. Storgård, E. Luoma, S. Mäntyniemi, S. Kuikka, "A Bayesian network for assessing the collision induced risk of an oil accident in the Gulf of Finland", Environmental Science \& Technology, Vol. 49, No. 9, pp. 5301-5309, 2015 